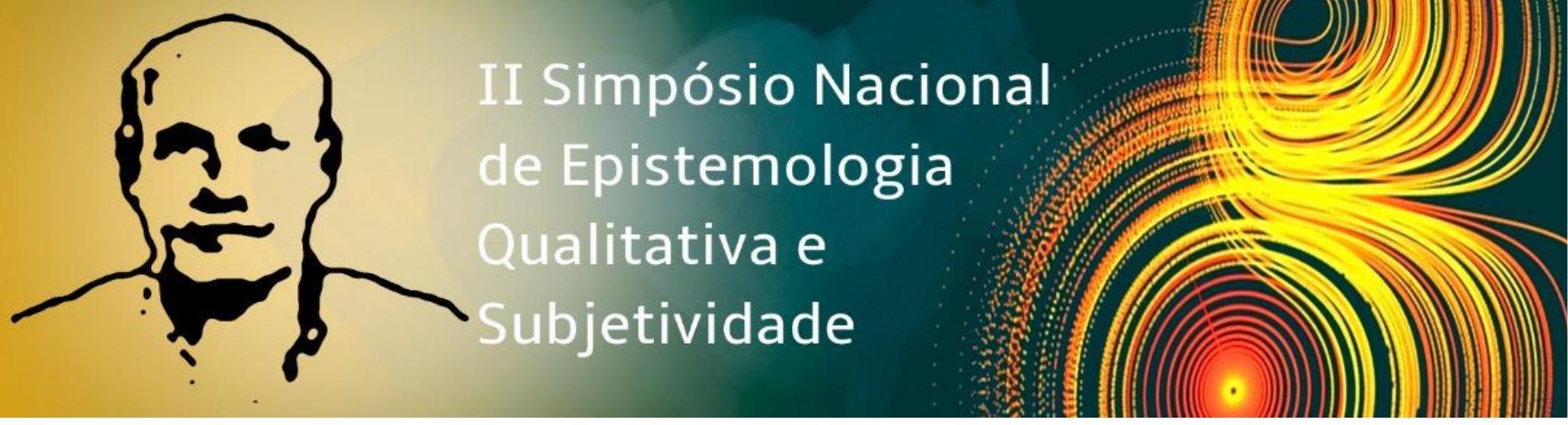

Eixo temático: 6. A subjetividade na formação de professores e outros profissionais

\title{
CONTRIBUIÇÕES DO USO DE JOGOS ANALÓGICOS PARA O PROCESSO DE APRENDIZAGEM DE UM ESTUDANTE DAS SÉRIES INICIAIS DO ENSINO
}

FUNDAMENTAL: Análises e desafios

\author{
Wellington dos Santos - SEEDF - wscafe@ hotmail.com \\ Elias Batista dos Santos - SEEDF; FAPRO - edrsantos@gmail.com
}

\section{Resumo}

Este artigo insere-se no contexto das atividades realizadas em uma escola pública de ensino fundamental em que, no espaço-tempo destinado à educação integral, foi desenvolvido um projeto, junto aos estudantes, para a confecção e utilização de jogos analógicos. O início da discussão sobre essa temática se deu quando, em conversas informais na hora do intervalo das aulas, os docentes identificaram a prevalência de jogos digitais em relação aos jogos analógicos no contexto institucional. Assim, contrapondo-se a esta tendência, este trabalho teve como objetivo analisar as contribuições da confecção e utilização de jogos analógicos para o processo de aprendizagem de um estudante do quinto ano do ensino fundamental. A partir dos princípios da teoria da subjetividade de González Rey e inspirados nos princípios da Epistemologia Qualitativa, utilizamos a análise documental, as conversas informais, o complemento de frases e a confecção de um desenho representativo para favorecer a produção e análise das informações. Os resultados indicaram que, no contexto da educação integral, a utilização do espaço-tempo destinado às atividades pedagógicas do contraturno dos estudantes para confecção e utilização dos jogos analógicos se constituiu como um lócus privilegiado para o exercício da criatividade, para a construção de uma relação pedagógica dialógica entre docente e discente e para a criação de uma ambiência favorável ao processo de aprendizagem e desenvolvimento humano, tanto do discente quanto do docente.

Palavras-Chave: subjetividade; jogos analógicos; aprendizagem.

\section{Introdução}

Este artigo insere-se no contexto das atividades realizadas em uma escola pública de ensino fundamental em que, no espaço-tempo destinado à educação integral, foi desenvolvido junto aos estudantes, um projeto para a confecção e utilização conjunta de jogos analógicos. $\mathrm{O}$ objetivo foi analisar as contribuições da confecção e utilização de jogos analógicos para o 


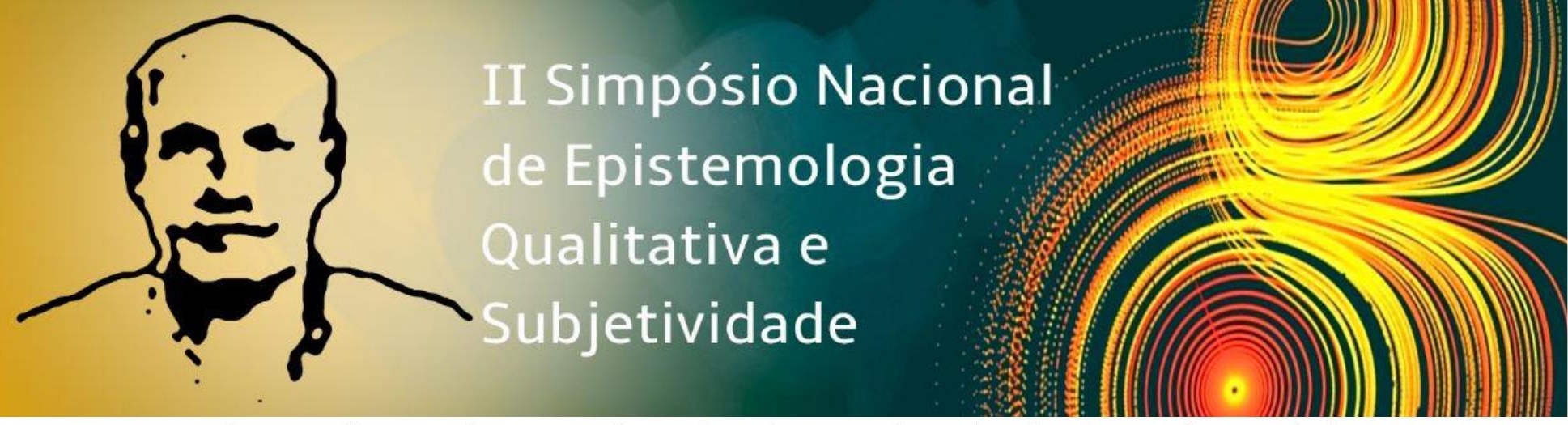

processo de aprendizagem de um estudante do quinto ano do ensino fundamental, a partir dos princípios da teoria da subjetividade de González Rey (2005). A teoria da subjetividade representa um sistema complexo, organizado, processual e dinâmico nos processos de aprendizagem e desenvolvimento humano (GONZÁLEZ REY, GOULARD e BEZERRA, 2016).

Já González Rey (2006, p. 35) conceitua sentidos subjetivos como “expressões de uma ideia simbólico-emocional na qual as emoções, sentidos e processos simbólicos de procedência muito diferentes integram-se na definição das diversas configurações subjetivas”. Sendo assim, os sentidos subjetivos representam um processo contínuo que emerge na experiência vivida e, ao mesmo tempo, a qualifica. Isto porque, a proposição da Teoria da Subjetividade assume uma "concepção dialógica e não instrumental dos sistemas de ações profissionais, atribuindo central importância à capacidade dos indivíduos e grupos de se posicionarem de forma ativa em seus diversos caminhos da vida, emergindo como sujeitos de suas próprias práticas". (GONZÁLEZ REY, GOULARD e BEZERRA, 2016, p. 856).

Com isso, a subjetividade pode ser entendida como uma produção singular que confere uma qualidade singular à experiência vivida pela pessoa. Nesse sentido, tanto indivíduos como grupos existem em redes relacionais vivas em cada um dos momentos concretos de uma ação, por meio da confluência, dinâmica e interdependente, de sentidos subjetivos e configurações subjetivas que se implicam estreitamente nesse momento (GONZÁLEZ REY, 2015). As configurações subjetivas expressam um processo que constitui a ação e que, simultaneamente, é constituído por ela.

Assim, nos inspiramos na metodologia construtivo-interpretativa para interpretar o processo de construção de informações produzidas no contexto das oficinas de jogos analógicos realizadas na unidade escolar. Segundo Rossato e Mitjáns Martinez (2018), a análise construtivointerpretativa se constitui como um processo marcado pela recursividade do processo analítico.

\section{Metodologia}

Nossa pesquisa se apoiou na perspectiva da epistemologia qualitativa construtivo-interpretativa (GONZÁLEZ REY e MITJÁNS MATÍNEZ, 2017), a característica marcante nesta metodologia é a relação equânime entre o pesquisador e o pesquisado, produzindo novos 


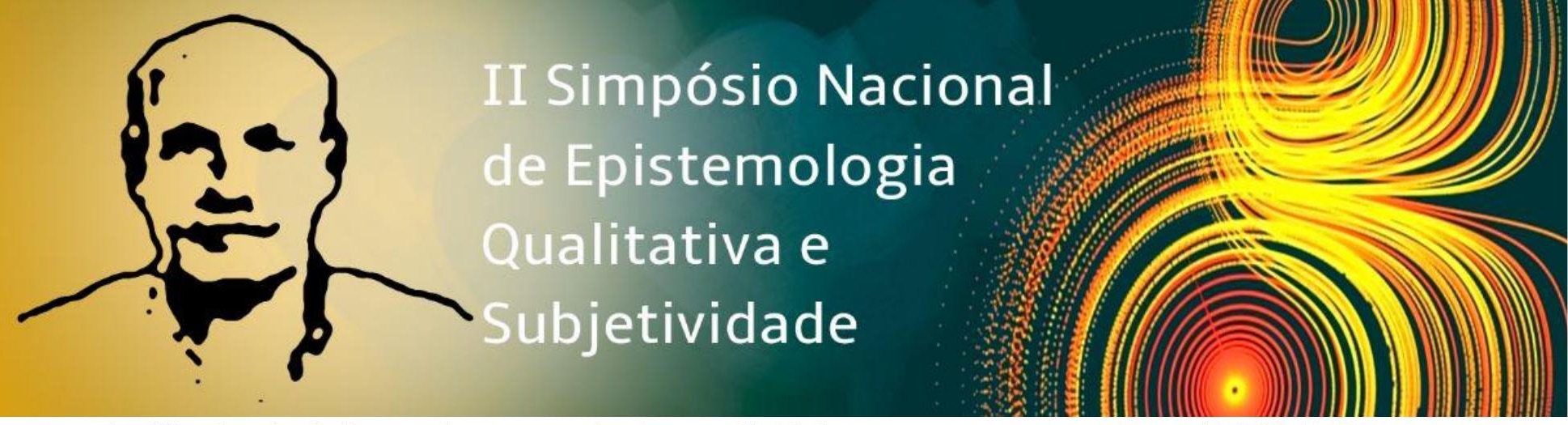

significados às informações por meio do ato dialógico entre os agentes. Para (ROSSATO, MITJÁNS MARTÍNEZ, 2017, p. 344)

O processo interpretativo é sempre uma produção de novo significado sobre eventos que, em seu relacionamento, não tem significados a priori. A interpretação das informações ocorre ao longo de toda a pesquisa e vai alimentando novas construções no processo.

Assim, os conceitos foram se constituindo de acordo com o desenvolvimento da pesquisa, pois o processo de construção da pesquisa foi vivo e aconteceu de acordo com o próprio desenvolvimento da produção teórica e do acompanhamento das oficinas para confecção e utilização de jogos analógicos (GONZÁLEZ REY; MITJÁNS MARTÍNEZ, 2017).

Nosso trabalho desenvolveu-se em uma escola de ensino fundamental da rede pública do Distrito Federal, no espaço-tempo destinado às oficinas pedagógicas ofertadas para estudantes da educação integral. Acompanhamos e analisamos as atividades pedagógicas realizadas durante o ano de 2018, depois de autorizados pelo corpo gestor da instituição e obtidos o consentimento de todas as pessoas voluntárias participantes da pesquisa.

Analisamos as contribuições da confecção e utilização de jogos analógicos para o processo de aprendizagem de estudantes do ensino fundamental das séries iniciais por meio da experiência vivida pelo estudante Carolo (nome fictício). A dinâmica conversacional durante a produção empírica implicou no convívio in loco e na criação de um cenário de pesquisa agradável e favorecedor da prevalência de um diálogo descontraído e informal nas aulas, o que nos permitiu configurar "comportamentos intencionais ou não-intencionais em seu contexto temporalespacial, independentemente da capacidade verbal expressiva dos sujeitos, estabelecendo pontos e contrapontos em relação às informações produzidas a partir dos instrumentos utilizados (ROSSATO, MITJÁNS MARTINEZ, 2017). Além disso, tivemos acesso ao projeto político pedagógico da instituição, aos relatórios pedagógicos e, foram utilizados indutores para facilitar a produção de informações pelos participantes, como, por exemplo, produção de desenho e complementação de frases.

\section{A escola}

A pesquisa foi feita em uma escola pública (que recebeu o codinome de "Escola Burca"). A região é constituída por novos loteamentos, advindos de chácaras desmembradas, e, como é recorrente, quando se começa um novo loteamento, é fácil notar a falta de infraestrutura, 


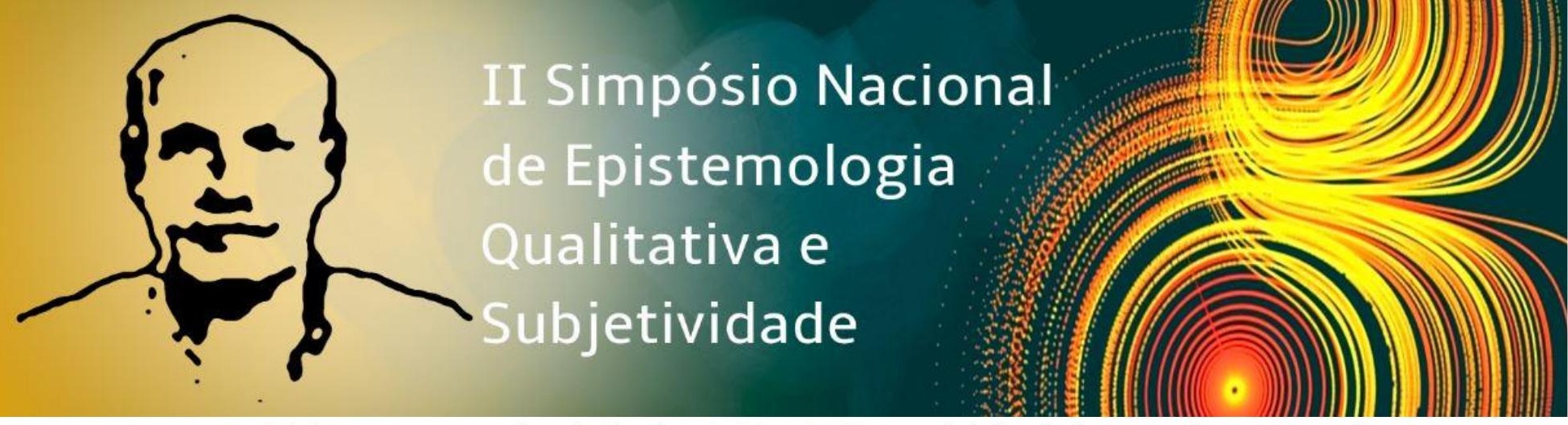

saneamento básico e excesso de violência. A Escola Burca foi fundada para dar suporte à comunidade local, e, atualmente, atende a duzentos estudantes. Em todo tempo da pesquisa o ambiente escolar foi considerado, pelos participantes, como sendo aconchegante e a equipe de trabalho como sendo comprometida.

\section{O docente}

Nascido em Brasília, no ano de 1982. Ingressou na Secretaria de Estado de Educação em 2014, para atuar nas séries iniciais. Chegou em 2018 para coordenar o projeto de Educação Integral da Escola Burca. Assim, quando assumiu o espaço-tempo da Educação Integral introduziu a confecção e utilização de jogos analógicos como atividade pedagógica para favorecer a expressão da ludicidade no contexto escolar, além tentar contrapor à prevalência de jogos digitais no contexto escolar.

\section{O discente}

Na Escola Burca funciona o projeto Educação em tempo Integral, que se organiza em oficinas diversas, sendo uma delas a oficina de "Jogos Analógicos com Bolas de Gude". É neste espaçotempo que Carolo, nascido em 2005, em Planaltina-DF, terceiro filho de uma família de cinco pessoas, estudante do $5^{\circ}$ ano do Ensino Fundamental, assumiu o protagonismo da confecção e utilização do jogo analógico futebol com bolas de gude.

Segundo conversas informais com docentes da instituição, Carolo, recorrentemente, se apresentava como tímido, pouco comunicativo e tinha dificuldades na compreensão dos conteúdos apresentados na sala de aula, sendo, comumente, o último da turma a realizar atividades. Por exemplo, ao cursar o $3^{\circ}$ ano, ficou retido por quatro anos consecutivos e, ao iniciar o quinto ano, a expectativa predominante entre os docentes era de que haveria nova retenção. Apesar dessas dificuldades, era recorrente no meio escolar a percepção de que Carolo, mesmo se apresentando, costumeiramente, pouco comunicativo e tímido, gostava de atividades recreativas e ações pedagógicas que envolvesse jogos e interação lúdica.

\section{O espaço-tempo da oficina de confecção e utilização de jogos analógicos}

No ano de 2018, teve início a oficina "Jogos Analógicos com Bolas de Gude" na Educação Integral. Assim, Carolo ficava na escola pela manhã fazendo atividades nas oficinas e, no período da tarde, ia para sala de aula. 


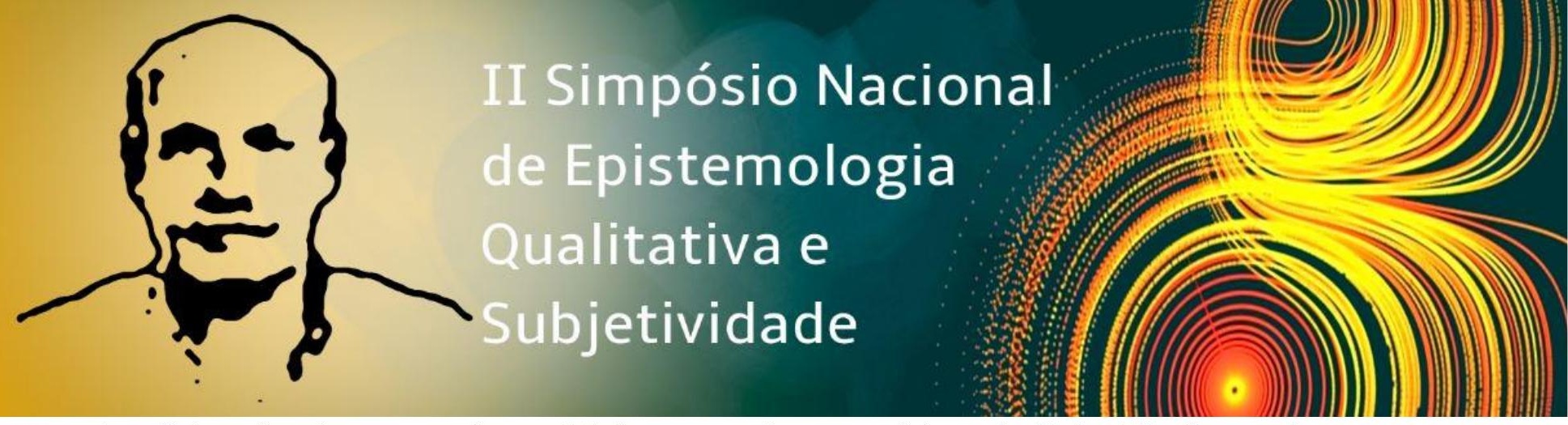

As oficinas funcionavam pela manhã, às terças e às sextas-feiras, de $9 \mathrm{~h}$ às $12 \mathrm{~h}$. Os estudantes chegavam, tomavam café da manhã, recebiam os avisos do dia e realizavam atividades relacionadas à confecção e utilização dos tabuleiros dos jogos outras ações necessárias para tornar o ambiente do jogo o mais lúdico possível. Em geral, essa oficina tinha duração média de $3 \mathrm{~h}$ (três horas), com participação de 40 estudantes.

Carolo jogava e, em outro momento, era juiz. Assim, assumia diversas funções frente aos demais estudantes. O Coordenador, na maioria das vezes, assumia as mesmas responsabilidades que Carolo, inclusive, jogando os campeonatos, o que favorecia a interação entre todos e a resolução de conflitos que surgiam ao longo das atividades programadas para a ocasião.

É importante ressaltar que esta oficina não era a preferida por todos os estudantes. Nesse sentido, havia estudante que não gostava de futebol e, muito menos de bolas de gude. Assim, para estes estudantes, no espaço-tempo destinado à oficina, eram disponibilizadas outras atividades pedagógicas, mais de acordo com o interesse que eles manifestavam. Essa situação corrobora com o entendimento de que cada pessoa subjetiva a realidade vivida de acordo com uma confluência dinâmica e subversiva de situações relativas, por exemplo, à produção de sentidos subjetivos, história de vida e subjetividade social. (GONZÁLEZ REY; MITJÁNS MARTÍNEZ, 2017).

A Copa do Mundo de Futebol com Bolas de Gude teve início com a fase das Eliminatórias, esta atividade consistia em selecionar 32 alunos para participar da competição, sendo que o primeiro momento foi de entendimento das regras do jogo, introdução da história da Copa e curiosidades das principais seleções. As eliminatórias aconteceram de fevereiro a abril de 2018. Nesse tempo, os participantes já dominavam regras e técnicas do jogo. Carolo foi o campeão das eliminatórias e, como primeiro da tabela de classificação, escolheu como seleção o Brasil. Em maio iniciou a Copa do Mundo, dividido os participantes em grupos, jogando todos entre si, em cada grupo de jogo, os dois participantes com maior pontuação seguiam para a próxima fase. No final da primeira quinzena de junho, realizou-se a final da Copa do Mundo de Futebol com Bolas de Gude, com a participação de toda a escola, os estudantes caracterizados com as seleções de sua preferência, e naquele momento, o Brasil de Carolo que chegava à final. A Escola Burca estava toda ornamentada nas cores das seleções finalistas, torcedores pintados e cantando músicas de apoio aos participantes, o que indicou, segundo nosso processo 


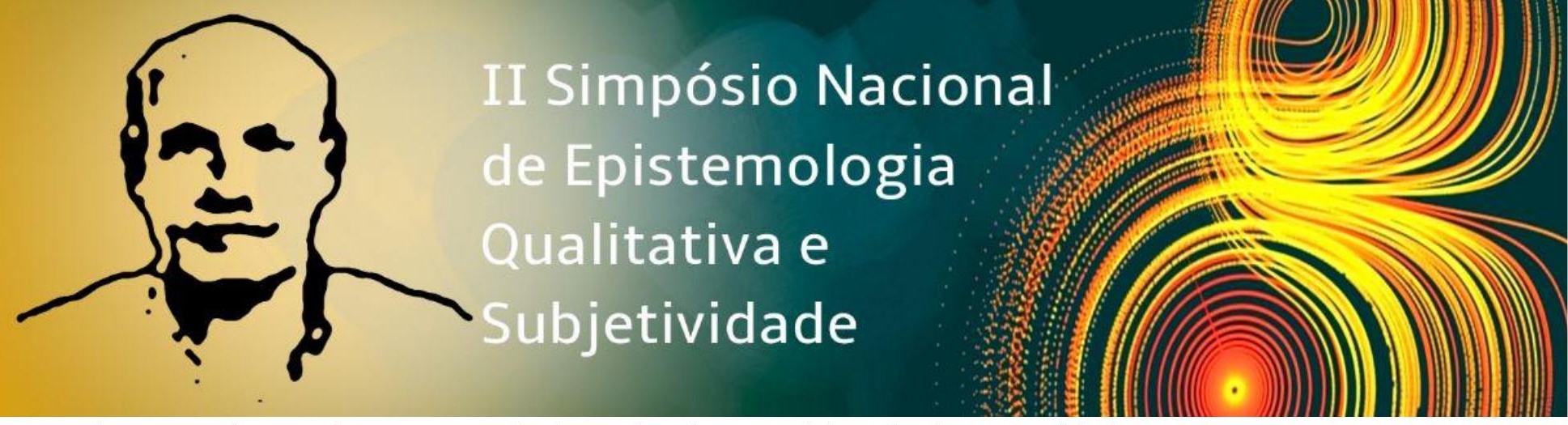

interpretativo, mais um exemplo da aceitação e participação da comunidade escolar, tanto na produção quanto na comemoração das atividades da oficina. (Carolo ganhou o jogo da final e foi o campeão desta edição da Copa do Mundo de Futebol com Bolas de Gude).

\section{Resultados e Discussão}

Durante a realização da atividade de complemento de frases, algumas situações chamaram nossa atenção. Carolo apresentou-se disponível para a prática de esporte e para as brincadeiras, ele respondeu as frases desta maneira: O jogo (Futebol), amo (Futegude - sigla de futebol com bolas de gude, utilizada nas oficinas), considero que posso (ganhar), competição (vitória), queria ser (jogador), meu maior desejo (jogar no Corinthians), sempre quis (ser um bom treinador); nas observações em seus relatórios da escola, conversas informais com a mãe e professores, foi frequente a referência ao gosto de Carolo por futebol. Em conversa informal após uma das partidas, Carolo nos disse que "gostava da emoção da disputa". Do nosso ponto de vista, a ação de jogar se constituía, para ele, a partir da produção de sentidos subjetivos em confluência com as possibilidades vivenciadas por ele no contexto do par dialético vitóriaderrota, tristeza-alegria, disputa-reconhecimento. Corroborando com esse nosso entendimento, os docentes de anos anteriores nos disseram, repetidas vezes, que ele sempre encontrava facilidade quando a atividade escolar e os conteúdos estavam relacionados, de alguma maneira, com jogos ou brincadeiras. Em uma das conversas informais que tínhamos quando da chegada ou saída dos estudantes, a mãe de Carolo, nos disse que por volta dos 3 anos de idade, ele teve um problema de saúde que afetou o coração e limitou o envolvimento dele em diversas atividades, principalmente o futebol. Segundo a mãe, essas atividades comprometiam sua condição de saúde e, por isso, deviam ser evitadas. Essa situação nos ajudou a refletir sobre situações ocorridas em diferentes momentos, em que Carolo repetidamente expressou seu desejo de ser jogador, entretanto, ao mesmo tempo, se lembrava de sua condição física, que se tornara uma limitação para ele. Sendo assim, é possível que Carolo tenha encontrado no espaçotempo da oficina situação favorável para expressar sua afeição ao futebol, sem comprometer sua saúde. Assim, alcançou destaque na oficina, no contexto de sua relação afetiva com o futebol e com os jogos, ao participar das atividades ele apresentava-se satisfeito. Essa percepção tornou-se recorrente nas diversas situações em que ele ensinava aos colegas, dirimia conflitos 


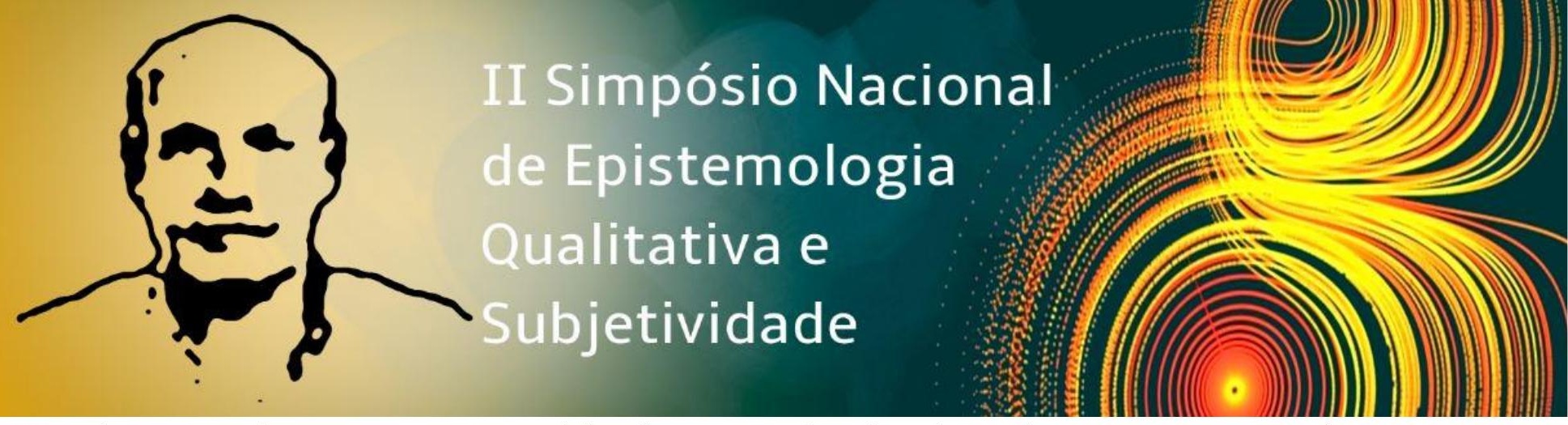

durante os jogos, atuava como juiz, dava sugestões de adaptações nas regras e, assim, conquistava respeito e admiração dos demais estudantes pela sua forma de jogar.

$\mathrm{Na}$ atividade de confeccionar um desenho de sua preferência, Carolo desenhou um campo de futebol e ao seu lado, o seu melhor amigo. Ao comentar sua produção, ele disse que gostava muito de brincar com este amigo, que para ser jogador precisa treinar e, se qualquer estudante quisesse vencer na vida precisaria estudar.

Notemos que ao mesmo tempo em que o espaço-tempo da oficina de jogos se constituiu como um lugar em que Carolo se sentia acolhido e feliz, a presença e participação de Carolo nas atividades da oficina contribuíram para a criação de uma ambiência favorecedora para a aprendizagem dos participantes. A relação, dialética e interdepende, entre o indivíduo e o grupo é explicada por González Rey, ao escrever que "individuo e grupos sociais tornam-se sujeitos de suas próprias ações quando eles são capazes de assumir decisões e posições que abra novos caminhos dentro do sistema social normativo em que as ações humanas são desenvolvidas". (GONZÁLEZ REY, 2018, p. 184, tradução livre).

Em relação ao trato familiar, Carolo produziu e expressou sentidos que nos ajudaram a compreender mais um pouco sobre sua história de vida. Por exemplo, no complemento de frase, escreveu: Minha mãe (legal), meu pai (chato), sonho (ser um bom filho), tenho medo (de não ser um bom filho), minha maior preocupação (a minha mãe). Esse conjunto de respostas, segundo nossa interpretação, indica uma expressão de afeto pela mãe. Recorrentemente, em nossas conversas informais, Carolo se referia a mãe com carinho e desejo de protegê-la. Certa vez, ele chegou a afirmar que tinha "muito medo de decepcionar minha mãe, quero que seja sempre feliz". Parece que Carolo se esforçava por, de alguma maneira, compensar o sofrimento que a mãe já viveu. Sendo assim, ele quer ganhar dinheiro "para não deixar nada faltar em casa e nem para a minha mãe" (Carolo, conversa informal). González Rey e Martinez (2017) destacam que a produção de sentidos subjetivos não é uma ação isolada da pessoa, pois emerge com as experiências da vida, a própria racionalidade humana está subordinada aos processos de subjetivação. Assim, o ambiente em que a pessoa estabelece seus relacionamentos pode favorecer o surgimento de novas experiências e oportunidades de mudanças, modificando as suas experiências e vivências e, ao mesmo tempo, sendo modificado pela ação do individuo. 


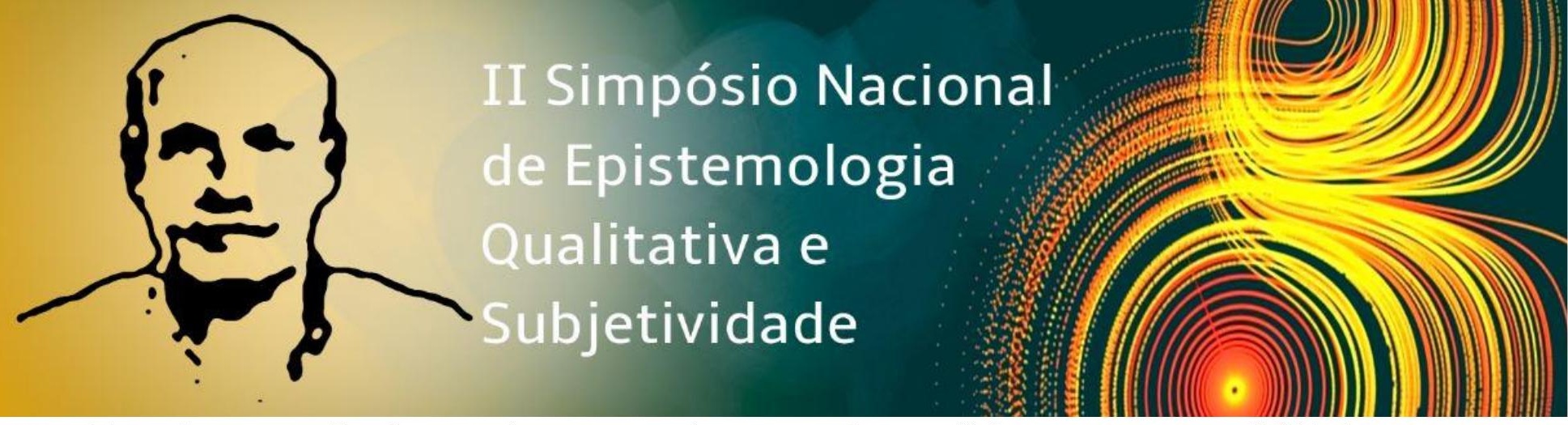

Entendemos que Carolo assumiu o protagonismo nas ações na oficina como uma possibilidade de trazer alegria para sua mãe, sendo assim, mobilizou recursos pessoais para se sair cada vez melhor nos desafios enfrentados no dia-a-dia da escola. Por sua vez, o espaço-tempo da oficina foi transformado pela presença e participação de Carolo, exemplo disso foi a ideia de Carolo referente às regras, quanto aos laterais e escanteios, em que antes eram aplicado dois toques na bola, e passou-se a utilizar três toques por jogador neste quesito, dando uma melhor dinâmica para o jogo e aumento de tempo na partida, aumentando o tempo de treino entre os colegas.

Assim, queremos destacar três momentos significativos de nossa construção teórica: a utilização do espaço-tempo para confecção e utilização dos jogos analógicos como um lócus privilegiado para o exercício da criatividade; a utilização do espaço-tempo para confecção e utilização dos jogos analógicos como um lócus privilegiado de construção de uma relação pedagógica dialógica entre docente e discente e a utilização do espaço-tempo para confecção e utilização dos jogos analógicos como um lócus privilegiado para a criação de uma ambiência favorável ao processo de aprendizagem e desenvolvimento humano. Sabemos que esses momentos não se constituíram de maneira sequencial ou estanque, entretanto, para facilitar a leitura do percurso construtivo-interpretativo que desenvolvemos, resolvemos apresentar as análises a partir da discussão desses momentos que consideramos significativos.

\section{Espaço-tempo para confecção e utilização dos jogos analógicos como um lócus privilegiado para o exercício da criatividade}

Com relação ao lócus privilegiado para o exercício da criatividade observamos que o processo cognitivo e afetivo estão imbricados com os processos de criação humana (RUNCO, 1996) as produções criativas estão implícitas no indivíduo e se complementam com auxílio do meio que ele vive, relacionando-se com suas próprias ideias e experiências ligadas ao seu contexto de vida, da configuração do meio que vive, onde envolve o ambiente e as pessoas. De acordo com Runco (1996, p. 04) “a criatividade é uma manifestação de intenções e de motivação para transformar o mundo objetivo em interpretações originais junto com a habilidade para decidir quando isso é útil e quando não é”. Carolo, neste cenário, expressou vontade de participar ativamente da oficina e se organizou para superar as dificuldades. 


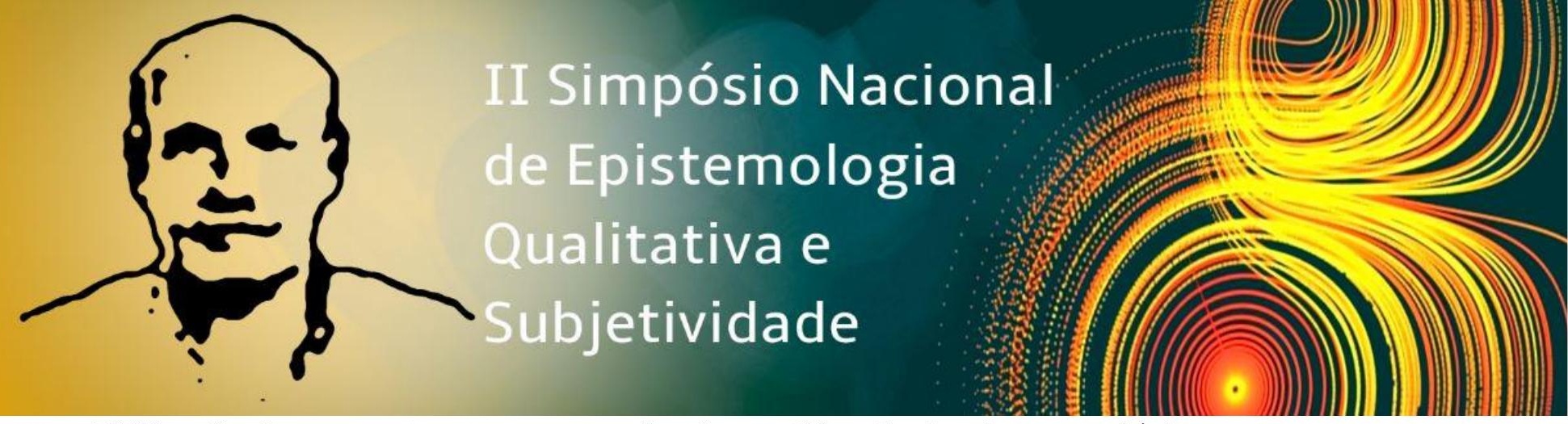

Utilização do espaço-tempo para confecção e utilização dos jogos analógicos como um lócus privilegiado de construção de uma relação pedagógica dialógica entre docente e discente

Durante o processo de desenvolvimento dos jogos analógicos, Carolo assumiu papel protagonista e se mostrou aberto ao diálogo com seus pares e com o docente. Para que as atividades propostas acontecessem, os participantes teriam que produzir materiais em conjunto. Essa situação de proximidade e compartilhamento de objetivos comuns favoreceu o desenvolvimento de uma relação pedagógica dialógica entre o docente e Carolo, em que o diálogo, a troca de experiências e a resolução conjunta de conflitos se constituíram como produtoras de sentido de amizade e confiança entre eles. Isto porque, segundo González Rey, Goulart e Bezerra (2016) "Os sujeitos, assim como suas configurações subjetivas, emergem de forma simultânea nos indivíduos e nas diferentes instâncias sociais em que se organiza sua vida social".

Utilização dos jogos analógicos como um lócus privilegiado para a criação de uma ambiência favorável ao processo de aprendizagem e desenvolvimento humano

O ambiente dos jogos analógicos favoreceu ao estudante um crescimento nas relações humanas como compreensão, cultura da paz, observada pelas situações de conflitos, que no início da oficina era bem acirrado, e com o tempo foi modificando, tornando o ambiente estável e acolhedor entre os estudantes. A utilização dos Jogos Analógicos no contexto da educação integral favoreceu a inserção de conteúdos escolares que desenvolvidos de maneira contextualizada, o que contribuiu no processo de aprendizagem dos discentes de forma participativa e criativa. Por exemplo, foi possível identificar a produção e expressão de conhecimento matemático quando os estudantes se organizavam para confeccionar as tabelas de jogos. Esta ação coletiva envolvia o uso correto das quatro operações, noções de geometria, habilidades técnicas de visão espacial, estratégia, pensamento criativo e cálculos mentais. Além disso, era necessário expressar conhecimento sobre a cultura de outros países e estados brasileiros, gêneros textuais, tomar decisões em consonância com os objetivos e recursos disponíveis no processo de criação do cenário em que os jogos aconteciam.

Como dito anteriormente, Carolo expressou durante o processo de escolarização algumas dificuldades em seu processo de aprendizagem. Durante as dinâmicas conversacionais, os 


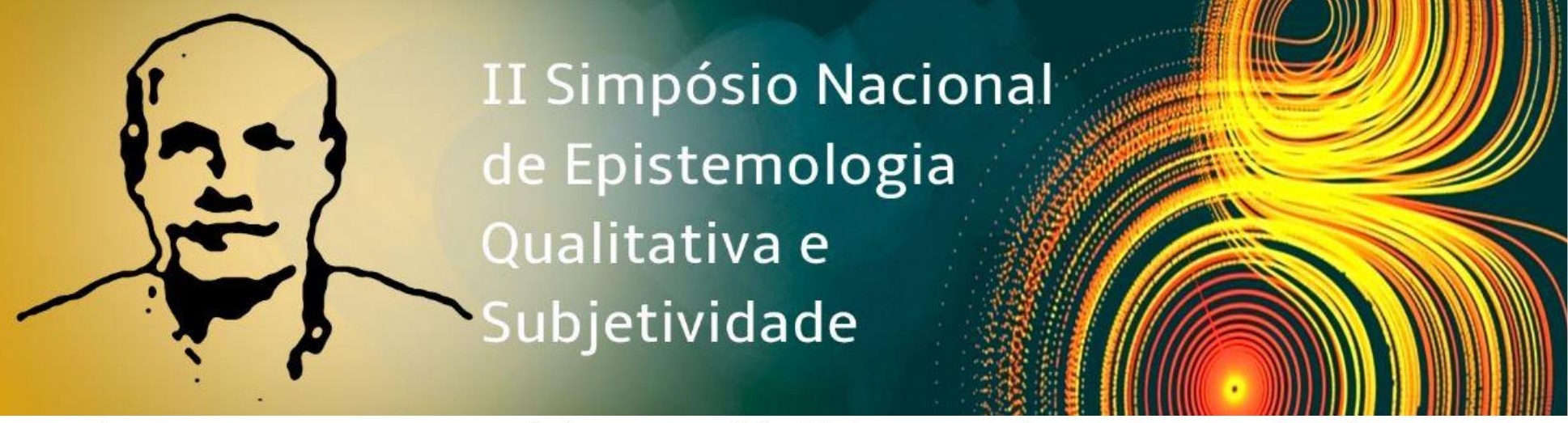

docentes recorrentemente se referiam a essa dificuldade apresentada por ele, o que incluía dificuldades com o conhecimento lógico matemático, a leitura e escrita, bem como a oralidade e a socialização. Durante sua participação nos jogos analógicos, Carolo pode exercitar a comunicação com seus pares, realizou cálculos matemáticos com acerto, participou da criação de estratégias de jogo e buscando compreender as regras, criou soluções para superação de dificuldades. Foi interessante perceber que ao mesmo tempo em que Carolo participava da oficina passou a apresentar melhor desempenho em sala de aula. Isto porque, tornou-se comum, ouvirmos na hora do intervalo, os docentes elogiando o desenvolvimento dele e os resultados positivos nas avaliações. Situação, até aquele momento, inédita na carreira estudantil dele. Por exemplo, no mês de novembro/2018, sua mãe disse "Carolo está diferente", se referia ao desejo de vir e permanecer o tempo todo na escola, à assunção de uma postura mais dedicada para realizar os deveres e estudar para as provas. Ainda em novembro, sua professora disse que Carolo se tornou finalista em um projeto de leitura em que as palavras sorteadas deveriam ser decodificadas e reproduzidas oralmente de forma correta por cada concorrente ("Nunca poderia imaginar isso no início do ano" - conversa informal professora de Carolo). Nos momentos de reunião pedagógica, tornou-se recorrente a menção à mudança que Carolo estava vivendo, destacando-se os comentários sobre sua aprendizagem e processo de socialização. Ao final do ano, contrapondo as expectativas iniciais, Carolo foi aprovado direto.

\section{Considerações Finais}

Nosso objetivo foi analisar as contribuições da confecção e utilização de jogos analógicos no processo de aprendizagem e desenvolvimento de um estudante do quinto ano do ensino fundamental de séries iniciais da Escola Burca, localizada no Distrito Federal. Carolo subjetivou as atividades realizadas no espaço-tempo da oficina a partir da produção e expressão de sentidos subjetivos, que de maneira interdependente e recursiva, constituíram a ambiência em que se desenvolviam as atividades sociais no contexto da oficina. Assim, sua contribuição subjetiva individual ajudou a construir um ambiente coletivo, criativo e aconchegante para ele, ao mesmo tempo em que este ambiente constituia o processo de transformação vivenciado por Carolo, como por exemplo, na sala de aula. Por sua vez, o docente ao promover o exercício da criatividade e a abertura ao diálogo no contexto das suas atividades na oficina favoreceu a 


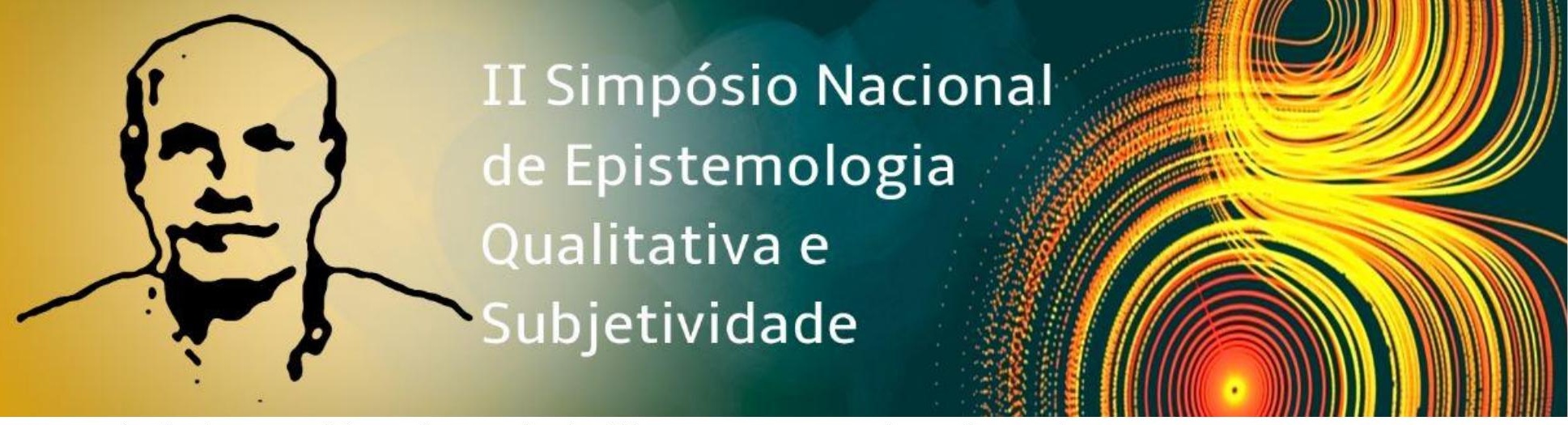

criação de um ambiente de respeito às diferenças e protagonismo do estudante, ao mesmo tempo em que, de maneira interdependente e recursiva, se constituía como autor do projeto de confecção e utilização de jogos analógicos como estratégia pedagógica.

Uma situação que se constituiu como desafio foi em relação à questão financeira, pois para a confecção e utilização de jogos analógicos na escola foi necessário dispor de um aporte financeiro. No caso da Escola Burca, os recursos foram alcançados por meio de doações, eventos ou recursos do próprio docente. O processo de superação das limitações físicas e estruturais para o desenvolvimento das atividades da oficina de jogos analógicos se constituiu como um espaço-tempo de aprendizagem e desenvolvimento humano tanto para o docente quanto para os estudantes.

Outra situação que destacamos é a necessidade de formação continuada do docente. É certo que a formação inicial não dá conta das especificidades que um docente vive no contexto da sala de aula. Assim, a abertura para processos de formação continuada pode ajudar o docente a assumir uma postura de autoria em relação à sua prática pedagógica, desenvolvendo possibilidades de aprendizagem e desenvolvimento profissional no contexto escolar.

Por fim, queremos destacar que para González Rey, Goulart e Bezerra (2016), em nosso sistema educacional, a não consideração da dimensão subjetiva da aprendizagem escolar favorece a negação da possibilidade do estudante se constituir como protagonista de sua própria aprendizagem. Em contraposição a essa possibilidade interpretativa, assumimos que a aprendizagem se dá em um processo subjetivo complexo e não apenas como um processo intelectual-instrumental. Nosso processo investigativo permitiu analisar uma ação pedagógica em que, por meio da confecção e utilização de jogos analógicos no espaço-tempo das atividades da educação integral, tornou-se possível a criação coletiva de um ambiente favorável à assunção do estudante como protagonista de sua aprendizagem.

\section{Referências}

González Rey, Fernando Luis. Sujeito e Subjetividade: uma aproximação histórico-cultural. São Paulo: Pioneira Thomson Learning, 2005.

A pesquisa qualitativa no campo da saúde: o estudo dos aspectos sociais e subjetivos da saúde humana. In: TACCA, Maria Carmen. (Org.) Aprendizagem e trabalho pedagógico. Campinas: Alinea, 2006, cap. 2. p. 29-44. 
